\title{
Cognitive impairment among institutionalized elderly individuals in Mysore, South India
}

\author{
Sharon Shatananda, Neha S. Leister, Bindu Annigeri, TS Satyanarayana Rao, LSS Manickam
}

\section{Introduction}

Identifying cognitive impairment in the elderly at an early stage has attained greater momentum in view of the increasing aged population in India. Different tools which are simple to administer as well as complex neuropsychological tests are available for assessment. RUDAS has been found to be useful in different contexts.

\section{Method}

A sample of 62 persons (29-men and 33-women) above the age of 60 was administered RUDAS and 31 of them had a score of $\geq 23$ and an equal number had scores below the cut off score.

\section{Results}

It was found that the total score as well as the sub score of visuo-constructional drawing of RUDAS were correlated with number of years of schooling.

\section{Conclusion}

RUDAS may be used as an effective tool to identify the persons with cognitive impairment at an early age.

SL J Psychiatry 2013; 4 (2):25-28

\section{Introduction}

The number of people with Alzheimer's disease and other dementias in India is increasing every year. It had been estimated that 24.3 million people worldwide and 1.8 million in India are affected by dementia (1). With the steady growth in the older population and increase in life expectancy, dementia is expected to increase two-fold by 2030 and three-fold by 2050 (2). A study conducted in India suggests that the elderly with dementia in the developing countries often do not make use of the health services (3). Even if they desire to do so, the health care system is not well equipped to provide them with the required services. However, early identification of dementia in the community assumes greater significance in order to formulate strategies for providing services for them. In addition, the impact of dementia on the individual, the family and the society at large, has not been studied extensively (4).

The need for identification or screening of dementia is gaining momentum and research is being conducted on various aspects related to dementia (5-6). Different screening tools are available to assess cognitive impairment and dementia. Some of there are; Rowland Universal Dementia Assessment Scale (RUDAS), General Practitioner Assessment of Cognition (GPCOG), Mini-Cog, Memory Impairment Screen (MIS), Mini Mental State Examination (MMSE), Six-Item Screener (SIS), Hopkins Verbal Learning Test, Vellore Screening Instrument for Dementia (VSID), Everyday Abilities Scale For India (EASI), Hindi Mental State Examination (HMSE), Informant Questionnaire on Cognitive Decline in the Elderly (IQCODE) Short Version, Community Screening Instrument for Dementia (CSID) and Kimberly Indigenous Cognitive Assessment (KICA) (6-10). A simple scale for detecting cognitive impairment that is culturally valid and easily administrable by primary health care clinicians would help identify those at risk at an early stage of their life. RUDAS is a short cognitive screening instrument designed to minimise the effects of cultural learning and language diversity on the assessment of baseline cognitive performance (11). RUDAS was used in a South Indian population to assess the cognitive impairment and found to have sensitivity similar to as that of MMSE and better specificity than MMSE (12). The cognitive domains assessed by RUDAS include memory, praxis, language, judgement, drawing and body orientation. The objectives of the study were to assess the cognitive impairment of the institutionalized elderly individuals and its socio demographic correlates.and to explore whether the individuals identified by the care-takers as having behavioural problems have any cognitive impairment.

\section{Methods}

\section{Sample}

The population consisted of 130 institutionalized elderly individuals living in a home, run by a nongovernmental organization. Of them, 62 (29-men and 33 - women) persons who were above the age of 60 and who had no visual or auditory disability or deficits in bilateral movements and consented to participate were included in the study. Among the sample, 41 (24-men and 17- women) persons were literate. Fifty two (29men and 23-women) persons were earlier engaged in occupations (Table 1).

\section{Measurement}

Rowland Universal Dementia Assessment Scale (RUDAS) is a six-item multicultural cognitive test, which takes about 10 minutes to administer. The six components of the scale are as follows: Memory (score of 8), body orientation (score of 5), praxis (score of 2), drawing (score of 3), judgement (score of 4) and language (score of 8). The maximum score is 30 and 
Table 1 - Socio-demographic data and the RUDAS score of the institutionalized elderly individuals

\begin{tabular}{|c|c|c|c|}
\hline & Males & Females & Total \\
\hline Total population & 65 & 65 & 130 \\
\hline Selected sample & 29 & 33 & 62 \\
\hline $\begin{array}{l}\text { Education } \\
\text { illiterate } \\
\text { Primary } \\
\text { Higher primary } \\
\text { High School } \\
\text { Higher secondary and } \\
\text { above } \\
\end{array}$ & $\begin{array}{l}05 \\
07 \\
04 \\
10 \\
03\end{array}$ & \begin{tabular}{|l}
16 \\
05 \\
05 \\
04 \\
02
\end{tabular} & $\begin{array}{l}21 \\
12 \\
09 \\
14 \\
05\end{array}$ \\
\hline $\begin{array}{l}\text { Occuptation } \\
\text { Nor worked before } \\
\text { Unskilled } \\
\text { Semi-skilled } \\
\text { Skilled } \\
\text { Professional }\end{array}$ & $\begin{array}{l}0 \\
03 \\
10 \\
15 \\
01\end{array}$ & \begin{tabular}{|l}
10 \\
01 \\
04 \\
15 \\
03
\end{tabular} & \begin{tabular}{|l}
10 \\
04 \\
14 \\
30 \\
04
\end{tabular} \\
\hline RUDAS score $<23$ & 14 & 17 & 31 \\
\hline
\end{tabular}

a score of 22 or less is considered as indicative of possible cognitive impairment.

\section{Procedure}

One of the authors (BA) had been visiting an institution for the elderly persons run by a non-governmental organization in Mysore, (South) India on a regular basis. The institution has a population of 130. During the visit to the institution, the care takers of the old age home identified 14 inmates as having behavioural problems and referred them for psychiatric evaluation. Of the fourteen, 5 were clinically found to have dementia as per the ICD 10 criteria. However the diagnosis of dementia and other psychiatric problems were known to the consultant Psychiatrist (BA). The RUDAS was administered by four psychologists who were blind to the clinical status of the individuals.

\section{Results}

The results showed that out of 62 (29-men, 33-women) individuals who were assessed, 31 (14-men, 17-women) scored below 23 which is indicative of possible cognitive impairment (table 1) (13). All five patients who were clinically diagnosed to have dementia also scored below the RUDAS cut-off. In addition, RUDAS score showed that 26 more inmates had significant cognitive impairment and it was equally distributed between the genders(table 3 ).

All the sub scores of RUDAS were significantly correlated with the total scores of RUDAS except for the visuo-constructional drawing (Table 3). The scores of visuo-constructional drawing was not correlated with any of the sub tests of RUDAS.

The total RUDAS score correlated with the years of schooling (table 4).

\section{Discussion}

Half of the institutionalized elderly individuals who took part in the study scored below the cut off score on RUDAS. But the caretakers were able to identify only five individuals $(16 \%)$ who had a clinical diagnosis of dementia as having cognitive impairment. However, it is important to observe that all five who were clinically diagnosed as having dementia could be identified through RUDAS. Since the onset of dementia is gradual, it is possible that the early stage of dementia is overlooked (14-15). The lack of awareness about cognitive impairment is also a factor which hinders early identification of dementia (16). Another reason for the caretakers not being able to identify those with cognitive impairment could be the short duration of time available to observe the inmates since some of them were recently admitted to the centre.

All the sub-scores of RUDAS correlated with the total score, indicating the internal consistency of the

\begin{tabular}{|l|l|l|l|l|l|l|}
\hline & Table 2 - RUDAS total and subscores according to gender, literacy and occupation \\
& $\begin{array}{l}\text { Male } \\
\text { N=29 } \\
\text { Mean (SD) }\end{array}$ & $\begin{array}{l}\text { Female } \\
\text { N=33 } \\
\text { Mean (SD) }\end{array}$ & $\begin{array}{l}\text { Literate } \\
\text { N=41 } \\
\text { Mean (SD) }\end{array}$ & $\begin{array}{l}\text { Illiterate } \\
\text { N=21 } \\
\text { Mean(SD) }\end{array}$ & $\begin{array}{l}\text { Worked before } \\
\text { N=52 } \\
\text { Mean(SD) }\end{array}$ & $\begin{array}{l}\text { Not worked } \\
\text { before } \\
\text { N=10 } \\
\text { Mean(SD) }\end{array}$ \\
\hline Memory & $5.24(2.64)$ & $6.48(1.66)$ & $6.05(2.43)$ & $5.62(1.86)$ & $5.85(2.27)$ & $6.20(2.20)$ \\
\hline $\begin{array}{l}\text { Visuo-spatial } \\
\text { orientation }\end{array}$ & $4.69(0.89)$ & $4.7(0.88)$ & $4.83(0.7)$ & $4.43(1.12)$ & $4.73(0.80)$ & $4.5(1.27)$ \\
\hline Praxia & $1.07(0.80)$ & $1.21(0.86)$ & $1.29(0.75)$ & $0.86(0.91)$ & $1.12(0.83)$ & $1.30(0.82)$ \\
\hline $\begin{array}{l}\text { Visuo constructional } \\
\text { drawing }\end{array}$ & $1.21(0.77)$ & $0.70(0.92)$ & $1.24(0.89)$ & $0.33(0.49)$ & $0.92(0.90)$ & $1.0(0.82)$ \\
\hline Judgement & $1.59(1.24)$ & $0.97(1.02)$ & $1.46(1.19)$ & $0.86(1.10)$ & $1.27(1.19)$ & $1.20(1.03)$ \\
\hline Language & $6.72(2.20)$ & $6.52(2.24)$ & $6.9(2.02)$ & $6.05(2.50)$ & $6.75(2.06)$ & $5.90(2.89)$ \\
\hline Total Score & $20.48(6.40)$ & $20.52(5.24)$ & $21.71(5.57)$ & $18.71(5.58)$ & $20.58(5.49)$ & $20.10(7.49)$ \\
\hline
\end{tabular}




\begin{tabular}{|c|c|c|c|c|c|c|}
\hline & Memory & $\begin{array}{l}\text { Visuo-spatial } \\
\text { orientation }\end{array}$ & Praxia & $\begin{array}{l}\text { Visuo } \\
\text { constructional } \\
\text { drawing }\end{array}$ & Judgement & Language \\
\hline Memory & - & & & & & \\
\hline $\begin{array}{l}\text { Visuo-spatial } \\
\text { orientation }\end{array}$ & $.433 * *$ & - & & & & \\
\hline Praxia & $.326 * *$ & $.333 * *$ & - & & & \\
\hline $\begin{array}{l}\text { Visuo constructional } \\
\text { drawing }\end{array}$ & . 079 & .185 & .237 & - & & \\
\hline Judgement & .249 & $.288^{*}$ & .217 & $.368 * *$ & - & \\
\hline Language & $.575^{* *}$ & $.496 * *$ & $.418^{* *}$ & .222 & $.527 * *$ & - \\
\hline Total Score & $.784^{* *}$ & $.64^{* *}$ & $.557 * *$ & $.410 * *$ & $.619 * *$ & $.874^{* *}$ \\
\hline
\end{tabular}

scale. However, the score of visuo-constructional drawing did not correlate with any of the other subtests of RUDAS, questioning the significance of visuoconstructional functions in dementia. Since there was a positive correlation between the number of years of schooling and total scoring, how far visuo-construction or "cube-copying" can be indicative of dementia or cognitive decline is to be verified. Storey et al, based on multivariate logistic regression have also observed that '3-dimensional drawing' and 'perfect copy' may not predict cognitive diagnosis (10). Though there was no significant difference between gender, occupation and RUDAS score, there was a significant correlation between number of years of schooling and RUDAS total score. A similar observation was made by Iype et al in a South Indian population using RUDAS (12). Storey et al in the multivariate logistic model also did not find the gender and years of education as the significant predictor of dementia (10). In the present sample, though the total score was related to schooling, only the subscales of visuo-constructional drawing was correlated with years of education which may challenge the role of visuo-constructional ability and its validity of predicting a cognitive diagnosis. A study conducted on the prevalence of dementia in association with education showed that the relative risk of dementia decreased with increasing level of education (17). There are other studies which showed a similar trend, wherein a higher prevalence of dementia was seen in less educated populations (18-20).

One of the strengths of this study is that the sample was assessed by those who were blind to the clinical diagnosis. However, since the data was collected from only one old age home the results have to be interpreted cautiously. Studies have shown that elderly with depression can present with dementia like picture
(21). Future studies should screening for persons with depression before administering RUDAS as research has shown that many individuals with Alzheimer's and other dementias have depressed mood and other behavioural symptoms, which can interfere with the cognitive functions (22). An extensive study in the urban and rural population may help validate the tool further.

Since the aging population is increasing and the number of individuals with cognitive impairment among the aged population also follow a similar trend, it is important that we develop simple tools like RUDAS that can be easily administered for the population in developing countries to help identify dementia at an early stage.

\section{Declaration of interest}

None declared

\section{Sharon Shatananda \\ Neha S. Leister \\ Bindu Annigeri, \\ T.S Satyanarayana Rao, \\ L.S.S Manickam}

Dept of Psychiatry, JSS Medical College, JSS University,

Mysore, India

Corresponding author

Sharon Shatananda

E mail: sharonshatananda@gmail.com

\begin{tabular}{|l|l|l|l|l|l|l|l|}
\hline & Table 4 - Correlation of the sub- scores of RUDAS with the number of years of schooling. \\
\hline & Memory & $\begin{array}{l}\text { Visuo-spatial } \\
\text { orientation }\end{array}$ & Praxia & $\begin{array}{l}\text { Visuo } \\
\text { constructional } \\
\text { drawing }\end{array}$ & Judgement & Language & Total score \\
\hline $\begin{array}{l}\text { Number } \\
\text { of years of } \\
\text { schooling }\end{array}$ & .044 & .213 & .173 & $.567^{* *}$ & .230 & .206 & $.285^{* *}$ \\
\hline
\end{tabular}




\section{References}

1. World Health Organization World Health Report 2003 — Shaping the future. WHO; Geneva: 2003.

2. Ferri CP, Prince M, Brayne C, Brodaty $\mathrm{H}$, Fratiglioni L, Ganguli $M$ et al. Global prevalence of dementia: A Delphi consensus study. Lancet, 2005, 366(9503) 2112-2117, 2005 Date of Publication:17 Dec 2005;366 (9503):2112-2117

3. Shaji KS, Kishore NR, Praveen LK, Prince M. Revealing a hidden problem. An evaluation of community Dementia care-finding program from the Indian 10/66 dementia research network. International journal of Geriatric Psychiatry 2002;17(3) (222-225).

4. Prince MJ. The $10 / 66$ dementia research group-10 years on. Indian J Psychiatry 2009;51:S8-15

5. Rao TSS, Shaji KS. Demographic aging: Implications for mental health. Indian j Psychiatry 2007; 49:78-80

6. Kathriarachchi ST, Sivayogan S, Jayaratna SD, Dharmasena SR. Comparison of three instruments used in the assessment of dementia in Sri Lanka. Indian J Psychiatry 2005; 47:109-112

7. Brodaty H., et al. The GPCOG: a new screening test for dementia designed for general practice. Journal of the American Geriatrics Society 2002; 50(3): 530-4.

8. Brodaty H., et al. What is the best Dementia Screening Instrument for General Practitioners to use? Am J Geriatr Psychiatry 2006;14:391-400.

9. Hogervorst E., et al. The Hopkins Verbal Learning Test and Screening for Dementia. Dement Geriatr Cogn Disord 2002;13:20

10. Grober E, Buschke H, Crystal H, Bang S, Dresner R. Screening for dementia by memory testing. Neurology 1988;38:900-903.

11. Storey JE, Rowland JT, Conforti DA, Dickson H.G., The Rowland Universal Dementia Assessment Scale (RUDAS): a multicultural cognitive assessment scale. International Psychogeriatrics 2004;16:1,13-31.

12. Iype $\mathrm{T}$, Ajitha BK, Antony $\mathrm{P}$, Ajeeth NB, Job $\mathrm{S}$, Shaji KS. Usefulness of Rowland Universal Dementia Assessment Scale in South India. Journal of Neurology. Neurosurgery \& Psychiatry 2006; 77(4), 513-514.
13. Kalaria RN, Maestre GE, Arizaga R, Friedland RP, Galasko D, Hall K, Lushsinger JA, Ogunniyi A, Perry EK, Potocnik F, Prince M, Wilmo A, Zhang ZX, Antuono P. Alzheimer's disease and vascular dementia in developing countries: prevalence, management and risk factors. Lancet Neurology 2008; 7: 812-26.

14. World Alzheimer Report. 2009. Alzheimer's Diseases International. Ref Type: Generic.

15. Brig. Saldanha D. An epidemiological study on dementia under the aegis of mental health program, Maharashtra, Pune chapter. Indian J Psychiatry 2010;52:131-139

16. Geda YE, Roberts O, Knopman DS, Petersen RC, Christianson TJ, Pankratz VS. Prevalence of neuropsychiatric symptoms in mild cognitive impairment and normal cognitive aging: Population-based study. Arch Gen Psychiatry 2008; 65:1193-8.

17. Zhang M, Katzman R, Jin H, Cai G, Wang Z, Qu G, et al. The prevalence of dementia and Alzheimer's disease (AD) in Shanghai, China: impact of age, gender and education. Ann Neurol 1990;27:42837.

18. Rocca WA, Banaiuto S, Lippi A, Luciani P, Turtu F, Cavarzeran F, et al.

19. Prevalence of clinically diagnosed Alzheimer's disease and other dementing disorders: a doorto-door survey in Appignano, Macerate Province, Italy. Neurology 1990;40:626-31.

20. Ott A, Breteler MB, Harskamp FV, Claus JJ, Cammen TJM, Grobbee DE, Hofman A. Prevalence of Alzheimer's Disease and Vascular Dementia: Association with Education. The Rotterdam Study. BMJ 1995;310:970-73

21. Katzman R. Education and the Prevalence of Dementia and Alzheimer's disease. Neurology 1993;43:13-20

22. Royall DR, Mahurin RK, Cornell J. Bedside Assessment of Frontal Degeneration: Distinguishing Alzheimer's Disease from NonAlzheimer's Cortical Dementia. Experimental Aging Research, 1994; 20, 95-103.

23. Teng E, Ringman JM, Ross LK, Mulnard RA, Dick $\mathrm{MB}$, Bartzokis $\mathrm{G}$, et al. Diagnosing depression in Alzheimer disease with National Institute of Mental Health provisional criteria. Am J Geriatr Psychiatry 2008; 16:469-77 